Kudryavtsev O.A., Sapozhnikov S.B., Zhikharev M.V. Numerical study of the influence of gaps between tiles and backing type on overall high-velocity impact performance of a ceramic-faced protective structure. PNRPU Mechanics Bulletin, 2019, no. 4, pp. 80-90. DOI: 10.15593/perm.mech/2019.4.08



ВЕСТНИК ПНИПУ. МЕХАНИКА

№ 4, 2019

PNRPU MECHANICS BULLETIN

http://vestnik.pstu.ru/mechanics/about/inf/

DOI: 10.15593/perm.mech/2019.4.08

УДК 539.3

\title{
NUMERICAL STUDY OF THE INFLUENCE OF GAPS BETWEEN TILES AND BACKING TYPE ON OVERALL HIGH-VELOCITY IMPACT PERFORMANCE OF A CERAMIC-FACED PROTECTIVE STRUCTURE
}

\section{O.A. Kudryavtsev*, S.B. Sapozhnikov, M.V. Zhikharev}

South Ural State University, Chelyabinsk, Russian Federation

\section{O CTATЬE}

Received: 24 May 2019

Accepted: 26 June 2019

Published: 30 December 2019

\section{Ключевые слова:}

ceramic composite panel, high-velocity impact, finite element analysis (FEA), mesoscale model.

\begin{abstract}
АННОТАЦИЯ
The intelligent design of lightweight, protective systems requires the use of numerical simulations widely to weed unsuccessful tests and minimise the number of expensive experiments. At the same time, it is necessary to have verified numerical models of all materials that are used in a protective structure to obtain adequate numerical simulation results. In this research, the impact performance of the ceramic-faced mosaic panel against the impactor with a complicated structure was studied using numerical simulations in thy commercially available package LSDYNA. Backing types being considered were Aluminium AA 5083 and Dyneema ${ }^{\circledR}$ HB80 UD composite. A new mesoscale model of $99.5 \%$ alumina based on the bonded particle method was calibrated and verified through the comparison with the known experimental data.

Further, designs with different configurations of mosaic ceramic layers having hex tiles were studied and compared. The results indicated that even small lateral gaps between ceramic tiles decreased the overall panel performance regardless of both the impact site and a backing type. At the same time, the presence of gaps reduces damages of the ceramic layer and can change the impactor trajectory that can be used in multi-layered structures with distant layers. Thus, it is necessary to find a balance between survivability and mass efficiency for each protective structure.
\end{abstract}

(C) Oleg A. Kudryavtsev - CSc in Technical Sciences, Research Engineer, e-mail: kudriavtcevoa@susu.ru, iD: 0000-0002-8530-3128

Sergei B. Sapozhnikov - Doctor of Technical Sciences, Professor, e-mail: sapozhnikovsb@susu.ru, ID: 0000-0002-7022-4865

Mikhail V. Zhikharev - Research Engineer, e-mail: zhikharevmv@susu.ru, iD: 0000-0001-6908-5768

(7) Эта статья доступна в соответствии с условиями лицензии Creative Commons Attribution-NonCommercial 4.0 International License (CC BY-NC 4.0)

This work is licensed under a Creative Commons Attribution-NonCommercial 4.0 International License (CC BY-NC 4.0) 


\section{Introduction}

Lightweight ceramic-faced structures are widely used for aircraft, vehicles, and personal protection against different high-velocity threats. Ceramic layer defeats or blunts a hard impactor core and spreads energy on a large area of a backing plate. The backing material, commonly made of composites or metals, must support the ceramic face layer during the penetration process and absorb the residual kinetic energy of both defeated impactor and ceramic debris.

Florence et al. [1, 2] and Wilkins et al. [3-5] published the earliest researches devoted to some important basic features of ceramic composite panel-impactor interaction. These works became the basis for all further studies in this area. Since then, the impact loading of high-strength fabrics and composites [6-13], ceramics [14-20], as well as their combinations [21-29], has been widely studied using both experimental and numerical approaches.

Most previous studies have focused on structures with a monolithic ceramic layer of a constant thickness. At the same time, a mosaic ceramic front layer is commonly used to enhance the multi-hit capability of a structure [30]. In this case, a monolithic ceramic plate is replaced by a panel consisted of ceramic tiles or cylinders that are embedded within a polymer-based matrix like polyurethane. There are also ceramic plates with geometric features like perforations or knobs on the front side [31]. On the authors' knowledge, only a few researchers studied ceramic-faced composite panels with untypical ceramic layer geometry.

Lanz et al. [32] studied two types of alumina tile configurations: with direct contact between tiles and with $1 \mathrm{~mm}$ rubber layer between them. The authors showed that the addition of damping components between ceramic tiles might reduce the amount of damage in a mosaic ceramic panel. Karandikar et al. [33] performed an experimental assessment of a ceramic tile geometry influence the highvelocity performance of the composite panel. For this purpose, ceramic tiles $(100 \times 100 \mathrm{~mm})$ with various geometric features such as perforations, blind perforations, knobs and cones on the front and the back sides were manufactured. High-velocity tests showed that a combination of rounded knobs on the front side and blind features in the back side of the ceramic plate allows increasing high-velocity limit velocity $\left(V_{50}\right)$ in comparison with a standard plate. Stanislawek et al. numerically studied several ceramic-faced composite panels with the front layer consisted of ceramic hemispheres [34], hexagonal bars [35, and tetrahedrons [36]. It was observed that the energy absorption capabilities of the multi-piece ceramic panel were easier to penetrate in comparison with a reference structure. Despite this fact, a mosaic ceramic layer was much less susceptible to overall fracture and demonstrated possibilities to change a projectile trajectory in some cases. Hazell et al. [37] evaluated the influence of ceramic tile size on a ceramic panel highvelocity performance. The authors manufactured $\mathrm{SiC}$ rectangular tiles with varying side's dimensions and tested them together with a backed polycarbonate layer. Also, numerical simulations were carried out to elucidate the penetration and failure mechanisms. It was shown that the strength of the failed material was considerably reduced due to the relative proximity of the radial boundary. Wang et al. [38] designed and characterized a lightweight hybrid composite panel target consisting of alumina ceramics pellets, ultrahigh molecular weight polyethene (UHMWPE), and two layers of Ti-6Al-4V. It was demonstrated that a rationally designed composite backing greatly enhanced the performance of a ceramic mosaic panel. All the researches mentioned above did not study an influence of ceramic mosaic layer geometry and imperfections like lateral gaps on high-velocity resistance of a full panel system properly.

The goal of this study was to develop a numerical approach to study how a distance between ceramic tiles influences an overall composite panel behaviour during highvelocity impact in cases different backings. For this purpose, the mesoscale numerical model of alumina ceramic was developed and verified. Calculations using the developed approach showed that a slight modification of the mosaic ceramic layer might change an overall composite panel resistance significantly.

\section{Ceramic material model}

Ceramic materials are inherently brittle. To consider deformation and fracture of brittle materials under high pressure and high strain rates, several constitutive models were developed and implemented into numerical codes. The Johnson-Holmquist strength and failure models (JH-1 and JH-2) [36, 37] are the most commonly used for modelling of ceramic material under the high-velocity impact. Examples of this model application can be found in [18, 28, 36, 37]. However, to determine the material parameters for numerical analysis, these models require a large number of expensive and complicated experiments like Depth-OfPenetration (DOP) tests. Most of the developed tests methods have several drawbacks such as limitation in tile thickness, wide variation in test results and response of the ceramic tile.

Moreover, tested specimens cannot be representative of a panel configuration [41]. Therefore, researches prefer to use already validated data for numerical analysis. At the same time, thousands of types of ceramics with significant scatter of properties are now being produced, but only a few have been studied enough to obtain reliable data for constitutive modelling.

The previous work [42] has shown that using of Discrete Element Method (DEM) is a good alternative to constitutive models for numerical simulations of ceramic target subjected to high-velocity impact. This approach allows obtaining both realistic fragmentations of ceramic target and reasonable agreement of calculated and experimental energy absorption. Moreover, the interaction of fractured ceramic material and intact structures (neighbour tiles and backing 
layer) can be easily considered, which is very important for the current study. Limitations of this approach were also discussed earlier.

\subsection{Material description}

In this work, all the calculations were performed for alumina ceramic AD-995 produced by CoorsTek. According to the manufacturer [43], the material has a density of $3.90 \mathrm{~g} / \mathrm{cm}^{3}$ and an average flexural strength of $379 \mathrm{MPa}$. The elastic modulus of the material is $370 \mathrm{GPa}$, and the Poisson ratio is 0.22 .

\subsection{Discrete Element Method in LS-DYNA and model parameters}

Discrete Element Method (DEM) is a discontinuous approach based on computing motions of a large number of particles. Implementation of DEM into LS-DYNA is explained in details elsewhere [44, 45], and just a brief overview is presented below. In LS-DYNA, the DEM is realised using rigid spherical particles by Cundall and Strack [46]. The calculations in DEM alternate the application of Newton's second law to the particles and a force-displacement law at the contacts. A penalty-based contact algorithm is used to capture particle-particle and particle-wall interaction. Interaction distance (see Fig. 1)

$$
d_{\text {int }}=R_{1}+R_{2}-\left|\mathbf{x}_{1}-\mathbf{x}_{2}\right|
$$

defines two collision states. When $d_{\text {int }} \leq 0$ mechanical contact occurs between the particles. There is no particleparticle interaction if $d_{\text {int }}>0$. The normal contact force is defined as

$$
F_{N}=K_{N} \cdot d_{\text {int }} \text { with } K_{N}=\frac{K_{1} \cdot R_{1} \cdot K_{2} \cdot R_{2}}{K_{1} \cdot R_{1}+K_{2} \cdot R_{2}} \cdot \text { NormK }
$$

where $K_{i}$ are the compression moduli of two neighbouring particles, $R_{1}$ and $R_{2}$ are the radii of particles. Setting the parameter NormK allows scaling of a penalty stiffness. The tangential spring constant is given relative to the normal spring constant

$$
K_{T}=K_{N} \cdot \text { ShearK }
$$

Suggested default values for NormK $=0.01$ and ShearK $=0.286$ were used in all simulations.



Fig. 1. Penalty-based particle-particle interaction
Defined loose spherical particles are bonded through special card *DEFINE_DE_BOND to model solid elastic material and brittle material fracture. All particles are linked to neighbouring particles through special bonds which are independent of the DEM model. Possible force and moment transmission modes include tension, compression, bending, shearing, and twisting (beam-like behaviour). The properties of the bonds are established by assigning parallel-bond modulus and shear stiffness/normal stiffness ratio. Maximum normal and shear stress for bond rupture define bond strength. By adjusting the bond radius multiplier, it is possible to bond each particle to several other particles. Thus, a few broken bonds can be interpreted as micro cracks, which finally transform to a macro crack.

The previous work [42] revealed that such parameters as discrete sphere radius and bond radius multiplier influence on results of numerical simulations. It was determined that a discrete sphere radius of $0.2 \mathrm{~mm}$ and corresponding bond radius multiplier of $0.52 \mathrm{~mm}$ allow obtaining a good agreement between experimental and numerical results in case of high-velocity impact onto alumina ceramic. These values we were used for all ceramic tiles directly subjected to projectile impact. Other tiles were modelled using a discrete sphere radius of $0.3 \mathrm{~mm}$ and corresponding bond radius multiplier of $0.6 \mathrm{~mm}$ on computational reasons. It may be done because the tiles were only boundary confinement for impacted pellets.

The parallel-bond modulus for both sphere radii was equal to the material elastic modulus - $370 \mathrm{GPa}$. Shear stiffness/normal stiffness ratio of 0.41 was determined based on the values of Poisson ratio of $v=0.22$ and elastic theory relation

$$
\frac{G}{E}=\frac{1}{2(1+v)}
$$

In order to determine bonds strengths and sliding/rolling friction, two different calibration procedures were carried out. The results of the calibrations are presented below.

\subsection{Bond strength calibration}

At the first stage of ceramic DEM modelling, it was necessary to determine bond strength. Bond strength assessment was performed through hybrid DEM/FEM threepoint bending test simulations for both discrete sphere radii. A specimen volume was modelled through bonded particles while usual finite elements were used for bearings. Numerical models were based on recommendations of ASTM C1161-13 standard [47] for the specimen's dimensions and shape (Configuration B). Fig. 2 demonstrates the numerical model for a sphere radius of $0.2 \mathrm{~mm}$ that was developed using LS-PrePost 4.3. The specimen had a width of $4.0 \mathrm{~mm}$, and a thickness of $3.0 \mathrm{~mm}$, and a length of $45 \mathrm{~mm}$. The radius of the bearings was $4.5 \mathrm{~mm}$. 
Average packing density was $49 \%$ and $51 \%$ for sphere radii of $0.3 \mathrm{~mm}$ and $0.2 \mathrm{~mm}$ respectively. In this connection, the density of discrete spheres was increased to keep overall density equals to a continuous one.

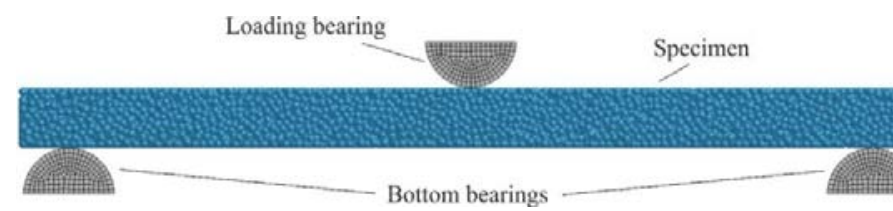

Fig. 2. The model for LS-DYNA simulation of the three-point bending test (front view) with a discrete sphere radius of $0.2 \mathrm{~mm}$

Discrete elements/finite elements interactions were realized using constraint-based node-to-surface contact definitions (*CONTACT_AUTOMATIC_NODES_TO_SURFACE with SOFT=1 on Optional Card A) with friction coefficient of 0.1 . Discrete elements were defined as the slave side, and finite-element structures (the piston and the bottom ring) were the master side. The top bearing was loaded by a linearly increasing force, whereas the flat surfaces of the bottom bearings were fixed (Fig. 2).

According to the standard [47], the relation between ceramic strength and peak force in three-point flexure for a rectangular specimen is as follows:

$$
S=\frac{3 P L}{2 b d^{2}},
$$

where $P$ is a break force, $L$ is a support span, $b$ is a specimen width and $d$ is specimen thickness. It is easy to evaluate that the peak force for the specimen with the average flexural strength of $379 \mathrm{MPa}$ is about $227 \mathrm{~N}$ for the test configuration $\mathrm{B}$. The bond strength was adjusted so that difference between a calculated force and break force did not exceed 5\%. Parallel-bond maximum shear stress was assumed to be equal to half of the parallel-bond maximum normal stress. The bearings were made of steel with a Young modulus of $200 \mathrm{GPa}$ and a Poisson ratio of 0.3. Calculation time was 1.0 millisecond. Progressive loading gives negligible kinetic energy (less than 5\%) and ensures a quasi-static aspect of the simulation.

Obtained bond strength parameters for both discrete sphere radius are listed in Table 1.

Table 1

\section{Calibrated bond strength}

\begin{tabular}{|c|c|}
\hline $\begin{array}{c}\text { Discrete sphere radius } \\
(\mathrm{mm})\end{array}$ & $\begin{array}{c}\text { Parallel-bond maximum normal stress } \\
(\mathrm{MPa})\end{array}$ \\
\hline 0.20 & 370 \\
\hline 0.30 & 450 \\
\hline
\end{tabular}

\subsection{Rolling and sliding friction calibration}

To choose correct values for rolling and sliding friction coefficients between discrete elements is of great importance. Shattered highly interlocked ceramic materials under projectile tip have a sufficient high-velocity performance [48] and greatly influence on penetration process.
Calibration procedures were based on two series of experiments performed by NII STALI JSC [49]. In these experiments, AD-995 hexagonal tiles with in-radius of 20 $\mathrm{mm}$ and thicknesses of $6 \mathrm{~mm}$ and $9 \mathrm{~mm}$ were backed with Armox 560T steel (thickness of $5 \mathrm{~mm}$ ) and AA5083 aluminium (thickness of $8 \mathrm{~mm}$ ) respectively. Areal density of panels was $63 \mathrm{~kg} / \mathrm{m}^{2}$ for alumina/steel composition and 57 $\mathrm{kg} / \mathrm{m}^{2}$ for alumina/aluminium one. Specimen's size was $100 \times 100 \mathrm{~mm}$. A projectile with a velocity of $830 \mathrm{~m} / \mathrm{s}$ [50] was used for testing of both types of fully clamped panels. Properties of the projectile are given in Table 2. In all the cases, there was no perforation.

Table 2

Properties of the projectile [50]

\begin{tabular}{|c|c|}
\hline Type & Property \\
\hline Jacket material & Mild steel \\
\hline Core material & Hardened steel \\
\hline Overall weight & $10.4 \mathrm{~g}$ \\
\hline
\end{tabular}

The tests mentioned above were reproduced numerically to estimate friction coefficients for the ceramic DEM model. Calibration was performed only for sphere radius 0.2 $\mathrm{mm}$. The friction coefficients for a sphere radius of $0.3 \mathrm{~mm}$ were assumed to be the same. This assumption was made because this sphere radius was used only for ceramic tiles which did not have direct contact with the projectile. Fig. 3 demonstrates the numerical model for alumina/steel simulations. No planes of symmetry were assumed in the model because of the random nature of the ceramic fracture.

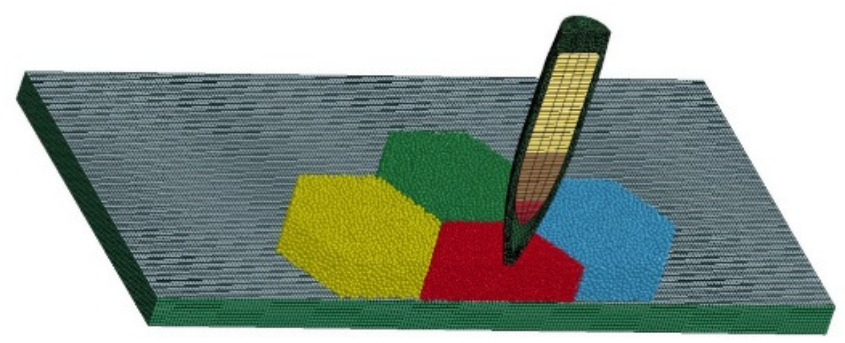

Fig. 3. The numerical model for alumina/Armox 560T steel impact simulations (section view)

The aluminium AA 5083 plate, the projectile hardened steel core, and mild steel jacket were modelled using Johnson-Cook (JC) material model [51] (*MAT_15) including strain hardening, strain rate effects and thermal softening:

$$
\sigma=\left[A+B\left(\varepsilon_{p}\right)^{n}\right]\left[1+C \ln \left(\frac{\dot{\varepsilon}_{p}}{\dot{\varepsilon}_{0}}\right)\right]\left[1-\left(\frac{T-T_{r}}{T_{m}-T_{r}}\right)^{m}\right]
$$

where $\sigma$ is the von Mises tensile flow stress, $A, B, C, m$ and $n$ are material-dependent constants, $\dot{\varepsilon}_{p}$ is the equivalent plastic strain rate, $\dot{\varepsilon}_{0}$ is the reference equivalent plastic strain rate, $T$ is the current temperature, $T_{r}$ is the room temperature, and $T_{m}$ is the melting temperature. A fracture occurs when the damage parameter 


$$
D=\sum \frac{\Delta \varepsilon_{p}}{\varepsilon_{p}^{f}}
$$

reaches the value of 1 . Here $\Delta \varepsilon_{p}$ is the incremental equivalent plastic strain during a cycle and $\varepsilon_{p}^{f}$ is the failure equivalent plastic strain defined as

$$
\begin{gathered}
\varepsilon_{p}^{f}=\left[D_{1}+D_{2} \exp D_{3}\left(\frac{\sigma_{m}}{\sigma}\right)\right] \times \\
\times\left[1+D_{4} \ln \left(\frac{\dot{\varepsilon}_{p}}{\dot{\varepsilon}_{0}}\right)\right]\left[1+D_{5}\left(\frac{T-T_{r}}{T_{m}-T_{r}}\right)\right] .
\end{gathered}
$$

In the above equation, $D_{1}, D_{2}, D_{3}, D_{4}$ and $D_{5}$ are dimensionless material constants and $\sigma_{m}$ is the average of the three normal stresses (mean stress). Johnson-Cook strength and failure parameters used in the simulations are shown below in Table 3.

Table 3

\begin{tabular}{|c|c|c|c|c|c|}
\hline Definition & $\begin{array}{c}\text { Sym- } \\
\text { bol }\end{array}$ & Unit & $\begin{array}{c}\text { AA5083 } \\
\text { aluminium } \\
{[52]}\end{array}$ & $\begin{array}{c}\text { Hardened } \\
\text { steel core } \\
{[53]}\end{array}$ & $\begin{array}{c}\text { Mild steel } \\
\text { jacket } \\
\text { [54] }\end{array}$ \\
\hline Density & $\rho_{0}$ & $\mathrm{~kg} \cdot \mathrm{m}^{-3}$ & 2700 & 7850 & 7850 \\
\hline Elastic modulus & $E$ & $\mathrm{GPa}$ & 70 & 210 & 210 \\
\hline Shear modulus & $G$ & $\overline{\mathrm{GPa}}$ & 27 & 80 & 80 \\
\hline Poisson ratio & $v$ & & 0.3 & 0.33 & 0.33 \\
\hline \multirow[t]{3}{*}{ Strain hardening } & A & $\mathrm{MPa}$ & 167 & 1576 & 448 \\
\hline & $B$ & $\mathrm{MPa}$ & 596 & 2906 & 303 \\
\hline & $n$ & & 0.551 & 0.1172 & 0.15 \\
\hline $\begin{array}{l}\text { Strain rate } \\
\text { hardening }\end{array}$ & $\mathrm{C}$ & & 0.001 & 0.00541 & 0.00333 \\
\hline $\begin{array}{l}\text { Reference strain } \\
\text { rate }\end{array}$ & $\dot{\varepsilon}_{0}$ & $\mathrm{~s}^{-1}$ & 1 & 1 & 1 \\
\hline \multirow{4}{*}{$\begin{array}{c}\text { Temperature } \\
\text { softening }\end{array}$} & $C_{p}$ & $\mathrm{~J} \cdot \mathrm{kg}^{-1} \cdot \mathrm{K}$ & 910 & 450 & 448 \\
\hline & $T_{r}$ & $\mathrm{~K}$ & 293 & 293 & 293 \\
\hline & $T_{m}$ & $\mathrm{~K}$ & 893 & 1800 & 1773 \\
\hline & $m$ & & 0.859 & 0.87 & 1.03 \\
\hline \multirow[t]{5}{*}{ JC failure } & $D_{1}$ & & 0.0261 & 0.0356 & 2.25 \\
\hline & $D_{2}$ & & 0.263 & 0.0826 & 0.0005 \\
\hline & $D_{3}$ & & -0.349 & -2.5 & -3.6 \\
\hline & $D_{4}$ & & 0.147 & 0 & 0.0123 \\
\hline & $D_{5}$ & & 16.8 & 0 & 0 \\
\hline
\end{tabular}

J-C strength parameters for AA5083 aluminium, projectile core and jacket

The Gruneisen equation-of-state (*EOS_GRUNEISEN) with cubic shock velocity-particle velocity $\left(v_{s}-v_{p}\right)$ was used. The Gruneisen equation is given as [45]

$$
p=\left\{\begin{array}{l}
\frac{\rho_{0} C^{2} \mu\left[1+\left(1-\frac{\gamma_{0}}{2}\right) \mu-\frac{a}{2} \mu^{2}\right]}{\left[1-\left(S_{1}-1\right) \mu-S_{2} \frac{\mu^{2}}{1+\mu}-S_{3} \frac{\mu^{3}}{(1+\mu)^{2}}\right]^{2}}+\left(\gamma_{0}+a \mu\right) E \quad \text { for } \mu \geq 0 \\
\rho_{0} C^{2} \mu+\left(\gamma_{0}+a \mu\right) E \quad \text { for } \mu<0
\end{array}\right.
$$

where $\rho_{0}$ is initial material density, $\rho$ is current density, $C$ is the intercept $v_{s}-v_{p}$ curve (sound speed), $\gamma_{0}$ is the Gruneisen coefficient, $a$ is dimensionless, first order volume correction to $\gamma_{0}$ and $\mu$ is defined by

$$
\mu=\frac{\rho}{\rho_{0}}-1
$$

where $S_{1}, S_{2}$, and $S_{3}$ are the coefficients of $v_{s}-v_{p}$ curve slope. Parameters of the Gruneisen EOS for aluminium plate, projectile core and jacket are tabulated in Table 4.

Table 4

Gruneisen equation parameters for AA5083 aluminium, projectile core and jacket used in simulations

\begin{tabular}{|c|c|c|c|c|c|}
\hline Definition & $\begin{array}{c}\text { Sym- } \\
\text { bol }\end{array}$ & Unit & $\begin{array}{c}\text { AA5083 } \\
\text { aluminium } \\
{[53,55]}\end{array}$ & $\begin{array}{c}\text { Hardened } \\
\text { steel core } \\
{[53]}\end{array}$ & $\begin{array}{c}\text { Mild steel } \\
\text { jacket } \\
{[54]}\end{array}$ \\
\hline Sound speed & $C$ & $\mathrm{~m}^{-1} \mathrm{~s}^{-1}$ & 5200 & 4596 & 4596 \\
\hline $\begin{array}{c}\text { Coefficients of } \\
v_{s}-v_{p} \text { curve } \\
\text { slope }\end{array}$ & $S_{1}$ & & 1.4 & 1.49 & 1.40 \\
\cline { 2 - 6 } & $S_{2}$ & $S_{3}$ & 0 & 0 & 0 \\
\hline $\begin{array}{c}\text { Gruneisen } \\
\text { coefficient }\end{array}$ & $\gamma_{0}$ & 0 & 0 & 0 \\
\hline $\begin{array}{c}\text { Volume } \\
\text { correction factor }\end{array}$ & $a$ & 1.9 & 1.93 & 1,93 \\
\hline
\end{tabular}

Armox 560T steel plate was modelled using modified Johnson-Cook (MJC) relation [56] (*MAT_107 in LSDYNA). For this model, the equivalent stress is expressed as

$$
\sigma=\left[A+B\left(\varepsilon_{p}\right)^{n}\right]\left[1+\frac{\dot{\varepsilon}_{p}}{\dot{\varepsilon}_{0}}\right]^{C}\left[1-\left(\frac{T-T_{r}}{T_{m}-T_{r}}\right)^{m}\right]
$$

where $A, B, C, m$ and $n$ are material constants. The rest parameters have the same meaning as in the original model (see equation (6) above). The temperature increment due to adiabatic heating is defined as

$$
\Delta T=\int_{o}^{\varepsilon_{p}} \chi \frac{\sigma}{\rho_{0} C_{p}} \mathrm{~d} \varepsilon_{p}
$$

where $\rho_{0}$ is the material density, $C_{p}$ is the specific heat and $\chi$ is the Taylor-Quinney coefficient which demonstrates ratio between heat and plastic work. Failure was specified using the Cockcroft-Latham (CL) fracture criterion [57]:

$$
W=\int_{o}^{\varepsilon_{p}} \max \left(\sigma_{1}, 0\right) \mathrm{d} \varepsilon_{p} \leq W_{c r}
$$

where $\sigma_{1}$ is the first principal stress, and $W_{\mathrm{cr}}$ is the critical value of the plastic work per unit volume. It should be noted that no additional EOS was specified for Armox 560T plate. Material constants for the numerical simulations are presented in Table 5.

*CONTACT_ERODING_NODES_TO_SURFACE was used to simulate interactions between the core and the jacket, the core and the metal plates, the ceramic and the metal parts (the core, the jacket and the metal plates). Contacts between the metal bodies were assumed to be frictionless, by Børvik et al. in Ref. [58]. The coefficient of friction between the ceramic tiles and the metal parts was 0.28 [59]. Bonding between the ceramic tiles and the metal plates was made using *CONTACT_TIED_NODES_TO_SURFACE algorithm. 
Table 5 The friction coefficients for discrete elements in this work

Parameters for Armox 560T steel modelling using MJC model [58]

\begin{tabular}{|c|c|c|c|}
\hline Definition & Symbol & Unit & Parameter value \\
\hline Density & $\rho_{0}$ & $\mathrm{~kg} \cdot \mathrm{m}^{-3}$ & 7850 \\
\hline Elastic modulus & $E$ & $\mathrm{GPa}$ & 210 \\
\hline Shear modulus & $G$ & $\mathrm{GPa}$ & 80 \\
\hline Poisson ratio & $v$ & & 0.33 \\
\hline \multirow{2}{*}{ Strain hardening } & $A$ & $\mathrm{MPa}$ & 2030 \\
\cline { 2 - 4 } & $B$ & $\mathrm{MPa}$ & 568 \\
\cline { 2 - 4 } & $n$ & & 1.0 \\
\hline Strain rate hardening & $\mathrm{C}$ & & 0.001 \\
\hline Reference strain rate & $\dot{\varepsilon}_{0}$ & $\mathrm{~s}^{-1}$ & 0.0005 \\
\hline Temperature softening & $C_{p}$ & $\mathrm{~J} \cdot \mathrm{kg}^{-1} \cdot \mathrm{K}^{-1}$ & 452 \\
\cline { 2 - 4 } & $T_{r}$ & $\mathrm{~K}$ & 293 \\
\cline { 2 - 4 } & $T_{m}$ & $\mathrm{~K}$ & 1800 \\
\cline { 2 - 4 } & $m$ & & 1.0 \\
\cline { 2 - 4 } & $\chi$ & & 0.9 \\
\hline CL failure & $W_{c r}$ & $\mathrm{MPa}$ & 2310 \\
\hline
\end{tabular}

Unfortunately, there was no information about boundary conditions during experiments, fully clamped edges of the metal plates (the worst case) were considered.

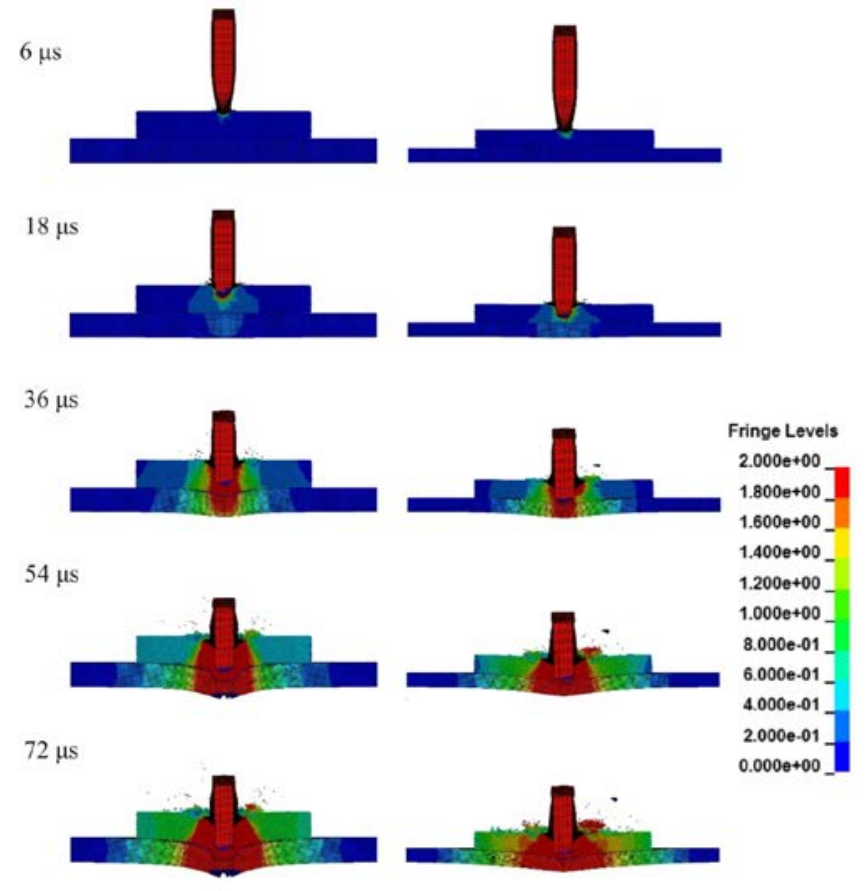

$90 \mu$ s



Fig. 4. Contours of result displacement for alumina/aluminium (a) and alumina/steel $(b)$ configurations obtained with calibrated friction coefficients

Several calibration simulations were performed with different values of sliding $\left(f_{\mathrm{s}}\right)$ and rolling $\left(f_{\mathrm{r}}\right)$ friction coefficients. Acceptable results were obtained with values of $f_{\mathrm{s}}=0.9$ and $f_{\mathrm{r}}=0.9$. For these values, there was no penetration for backed layers and corresponding ceramic thicknesses. should be considered only as "tunable" parameters, and they can be different for other discrete sphere radii. Results of simulations with the calibrated friction coefficients are presented in Fig. 4.

It is seen that in both cases there was a cone formation under the projectile despite the mosaic structure of a front ceramic layer. However, the cone of highly fractured material was less distinct for thinner ceramic tiles, and the damaged area was higher.

\section{Ceramic panel modeling}

\subsection{Description of full ceramic-faced panel models}

The basic motivation of the design study was to see how different lateral gaps between ceramic tiles affected overall panel behaviour. These gaps may be introduced deliberately to reduce the damage of neighbour pellets during impact or due to shape imperfections of ceramic elements. The developed and validated alumina model was used to study the behaviour of the panel plate with different configurations of mosaic ceramic tiles. In addition to Aluminium AA 5083, previously discussed and verified yarn-level model of UHMWPE composite Dyneema ${ }^{\circledR}$ HB80 [60] was also used for the analysis of backing type influence on the high-velocity performance of the mosaic panel. Mosaic front layer consisted of hex tiles with the same sizes as during the calibration procedures. Specimen's size being considered was $100 \times 100 \mathrm{~mm}$. Edges of panels were clamped. No planes of symmetry were specified in order to allow the possibility of projectile trajectory changes during impact. The projectile had a velocity of $830 \mathrm{~m} / \mathrm{s}$.

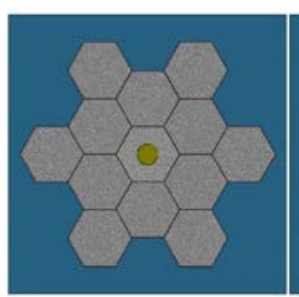

$a$

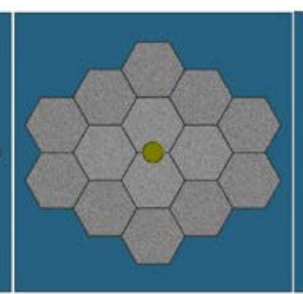

$b$

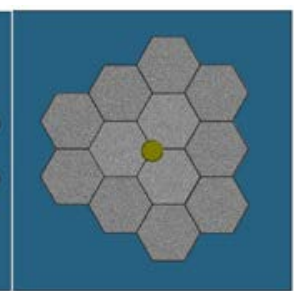

C
Fig. 5. Impact cases for panel analysis: (a) Case I: direct impact on the centre of a ceramic tile, (b) Case II: impact on the conjunction of two tiles, and (c) Case III: impact on the conjunction of three tiles

Three typical impacting sites (Fig. 5) were chosen for analysis of ceramic panel behaviour. For these three cases, different lateral distances between hexes - zero gaps, $0.5 \mathrm{~mm}$ and $1 \mathrm{~mm}$ - were considered for both composite (Dyneema ${ }^{\circledR}$ HB80) and aluminium (AA 5083) backings. The thickness of the aluminium layer was $8 \mathrm{~mm}$. The thickness of Dyneema ${ }^{\circledR}$ HB80 (8 mm) laminate was chosen based on preliminary calculations. Thus, areal densities of considered alumina/aluminium and alumina/UHMWPE composition were $57 \mathrm{~kg} / \mathrm{m}^{2}$ and $43 \mathrm{~kg} / \mathrm{m}^{2}$, respectively. 
Also, simulations with a reduced and increased strength of ceramic tiles (200 MPa and $500 \mathrm{MPa}$ respectively) were undertaken for the first impact case and zero gaps between the elements. It was done through changing of particleparticle bond strength.

\subsection{Results and discussion}

Table 6 summarises results of the simulations. Alumina/aluminium and alumina/UHMWPE composition demonstrated quite a different behaviour during high-velocity impact. Fig. 6 shows the relation between core velocity vs time for both types of backings (Case I, zero gaps).

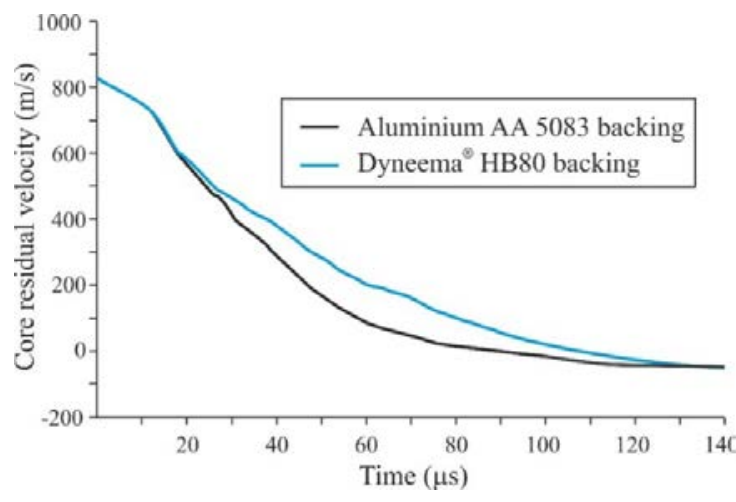

Fig. 6. Projectile core residual velocity versus time

Core projectile velocity decreases more steeply in case of alumina backing. Moreover, the projectile core velocity changes sign after $90 \mu \mathrm{s}$. The same moment for Dyneema ${ }^{\circledR}$ HB80 backing takes place only at 105-110 $\mu$ s. From Fig. 7, it appears that final projectile core lengths were less in all impact cases for aluminium backing.

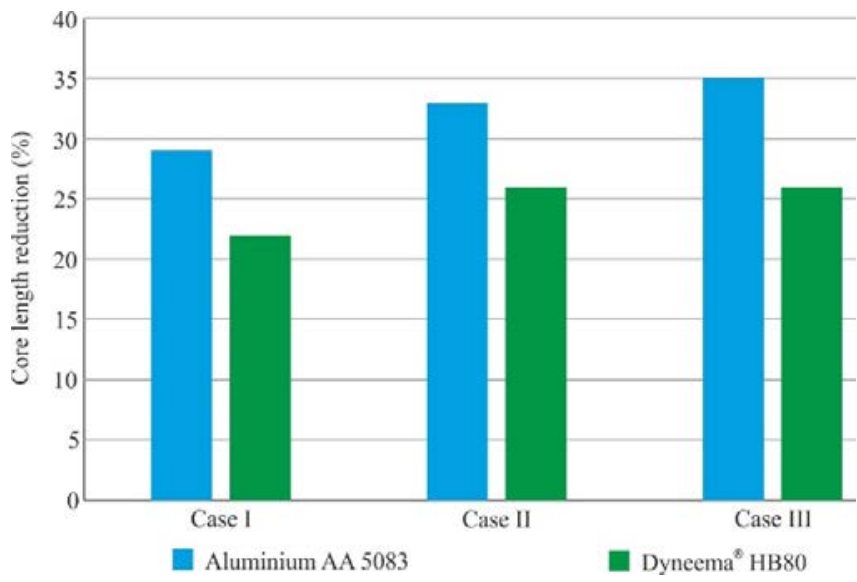

Fig. 7. The core length reduction as a function of backing for three impact cases

It is also remarkable that back side deflection (see Table 6) for the aluminium backing is also smaller. These facts can be explained by significant differences in backing transversal stiffness. Aluminium AA 5083 is a quite isotropic material, and its transversal stiffness is very close to the elastic modulus of $70 \mathrm{GPa}$. At the same time, the elastic modulus of Dyneema ${ }^{\circledR}$ HB80 in $\mathbf{z}$-direction does not exceed
1.5 GPa. Thus, the aluminium provides much stronger support for the ceramic layer and increases its effectiveness.

Table 6

A summary of all impact simulations results, showing backing deflection and final core length

\begin{tabular}{|c|c|c|c|c|c|c|}
\hline $\begin{array}{l}\text { Impact } \\
\text { case }\end{array}$ & $\begin{array}{c}\text { Lateral } \\
\text { gaps } \\
(\mathrm{mm})\end{array}$ & Backing & $\begin{array}{l}\text { Stopping } \\
\text { or } \\
\text { penetra- } \\
\text { tion }\end{array}$ & $\begin{array}{c}\text { Back } \\
\text { side } \\
\text { deflec- } \\
\text { tion } \\
(\mathrm{mm})\end{array}$ & $\begin{array}{c}\text { Residual } \\
\text { core } \\
\text { length } \\
\text { (mm) }\end{array}$ & $\begin{array}{c}\text { Core } \\
\text { length } \\
\text { reduc- } \\
\text { tion (\%) }\end{array}$ \\
\hline \multirow{6}{*}{ Case I } & \multirow[b]{2}{*}{0} & AA 5083 & $\mathrm{~S}$ & 5.57 & 20.3 & 29 \\
\hline & & $\begin{array}{c}\left.\text { Dyneema }^{(}\right) \\
\text {HB80 }\end{array}$ & $\mathrm{S}$ & 8.37 & 22.1 & 22 \\
\hline & \multirow[b]{2}{*}{0.5} & AA 5083 & $\mathrm{P}$ & & 21.7 & 24 \\
\hline & & $\begin{array}{c}\text { Dyneema }^{(B)} \\
\text { HB80 }\end{array}$ & $\mathrm{P}$ & & 22.5 & 21 \\
\hline & \multirow[b]{2}{*}{1} & AA 5083 & $\mathrm{P}$ & & 21.7 & 24 \\
\hline & & $\begin{array}{c}\text { Dyneema }^{\circledR} \\
\text { HB80 } \\
\end{array}$ & $\mathrm{P}$ & & 23.4 & 18 \\
\hline \multirow{6}{*}{ Case II } & \multirow[b]{2}{*}{0} & AA 5083 & $\mathrm{~S}$ & 4.28 & 19.0 & 33 \\
\hline & & $\begin{array}{c}\text { Dyneema }^{\circledR} \\
\text { HB80 }\end{array}$ & S & 7.13 & 21.2 & 26 \\
\hline & \multirow[b]{2}{*}{0.5} & AA 5083 & $\mathrm{P}$ & & 21.2 & 26 \\
\hline & & $\begin{array}{c}\text { Dyneema }^{\circledR} \\
\text { HB80 }\end{array}$ & $\mathrm{P}$ & & 23.0 & 19 \\
\hline & \multirow[b]{2}{*}{1} & AA 5083 & $\mathrm{P}$ & & 22.1 & 22 \\
\hline & & $\begin{array}{c}\text { Dyneema }^{(B)} \\
\text { HB80 }\end{array}$ & $\mathrm{P}$ & & 23.8 & 16 \\
\hline \multirow{6}{*}{ Case III } & \multirow[b]{2}{*}{0} & AA 5083 & $\mathrm{~S}$ & 4.27 & 18.6 & 35 \\
\hline & & $\begin{array}{c}\text { Dyneema }^{\circledR} \\
\text { HB80 }\end{array}$ & S & 7.39 & 21.2 & 26 \\
\hline & \multirow[b]{2}{*}{0.5} & AA 5083 & $S$ & 6.11 & 21.2 & 26 \\
\hline & & $\begin{array}{c}\text { Dyneema }^{\circledR} \\
\text { HB80 }\end{array}$ & $\mathrm{P}$ & & 25.2 & 12 \\
\hline & \multirow[b]{2}{*}{1} & AA 5083 & $\mathrm{P}$ & & 25.6 & 10 \\
\hline & & $\begin{array}{c}\left.\text { Dyneema }^{(}\right) \\
\text {HB80 }\end{array}$ & $\mathrm{P}$ & & 25.2 & 12 \\
\hline $\begin{array}{l}\text { Case I, } \\
\text { increa- } \\
\text { sed } \\
\text { strength } \\
\end{array}$ & 0 & AA 5083 & S & 4.53 & 18.2 & 36 \\
\hline $\begin{array}{l}\text { Case I, } \\
\text { reduced } \\
\text { strength }\end{array}$ & 0 & AA 5083 & $\mathrm{P}$ & & 23.4 & 18 \\
\hline
\end{tabular}

A delamination area was assessed through a pattern of matrix elements removed from the calculation due to failure. Fig. 8 demonstrates a pattern of matrix elements after the impact for all the three impact cases and three variants of lateral gaps between ceramic tiles.

Impact site influenced on delamination area only in cases of projectile stopping. When panels were perforated elements pattern were approximately the same. It is an interesting fact that among the configurations with zero gaps between the tiles, the worst one was Case I (11 not penetrated layers). The damaged area was more than in the other two cases as well as the back side deflection. Case II and Case III had a better performance, but in Case II, the number of non-penetrated layers was 25 while in Case III, it was only 20. Thus, the impact on the conjunction of two tiles is the least dangerous case when there are no gaps between tiles.

Moreover, a similar tendency was observed for aluminium backing. Core length changes and back side deflections for these two cases were higher than in Case I. Obtained results showed that behaviour of the mosaic panel consisted 
of hex tiles differs from that for a composite panel with ceramic layer assembled from cylinders. Liu et al. in Ref [61] observed that impact on the conjunction of three ceramic cylinders was the worst situation for the multi-piece ceramic panel. Destruction of the projectile was significantly less in comparison with two others (similar to Cases I and II). The dissimilarity can be explained by the existence of large gaps between three cylinders, whereas hexes were positioned without gaps and behave like a large plate with throughthickness cracks.

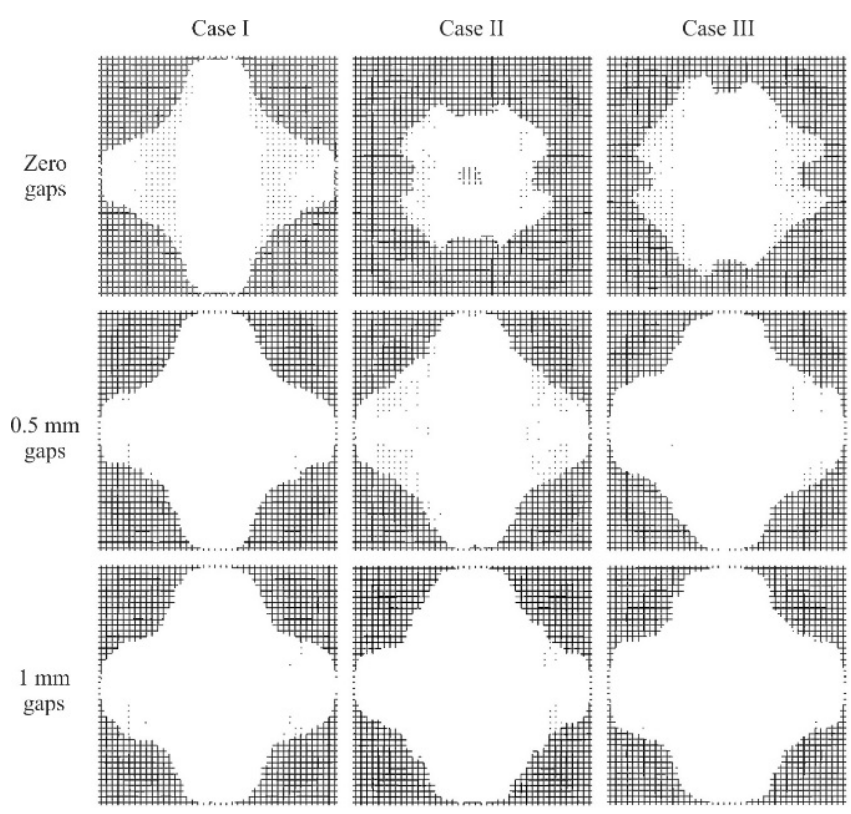

Fig. 8. Matrix elements patterns for Dyneema ${ }^{\circledR} \mathrm{HB} 80$ after impact

Presence of the gaps between hex tiles led to mixed results. On the one hand, there was no doubt that panel performance reduced for both types of backing. Among all considered configurations of the mosaic panel with gaps only in one case (Case III, aluminium backing and $0.5 \mathrm{~mm}$ gaps) there was no perforation. Core erosion decreased with increasing gaps. Relations between core lengths reduction and gap sizes for each impact case are presented in Fig. 9.

This fact is related to insufficient support of impacted tiles by neighbour ones. Comminuted ceramic material under projectile did not work effectively and transmitted projectile kinetic energy to the small area of backing, which was insufficient for successful projectile stopping. On the other hand, overall damages of the mosaic layer with gaps were less in comparison with the configurations without any distances between tiles. As an example, images of overall displacements in ceramic layers after impact for plates with direct contact and $1 \mathrm{~mm}$ gaps between tiles (Case I) are presented in Fig. 10.

Here it should be noticed that the simulations were performed without consideration of gap filling. At the same time, different fillers like polyurea may have a noticeable influence on ceramic layer damages because of their energy absorption capabilities under impact loading [62]. For this reason, further research will be conducted in this area.

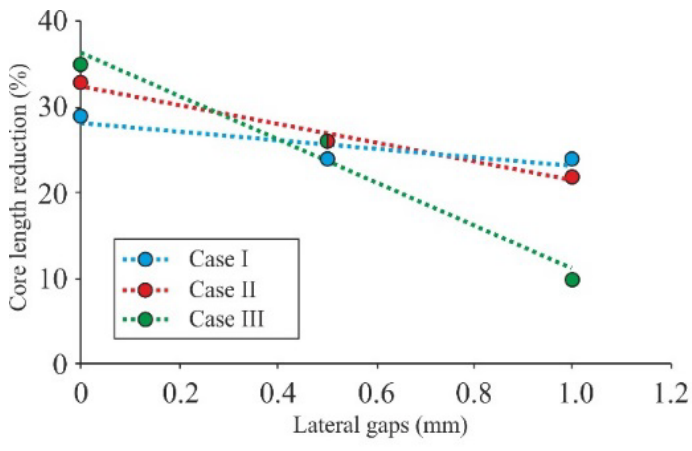

$a$



Fig. 9. Core length reduction versus gap between ceramic tiles: (a) Aluminium AA 5083 backing, (b) Dyneema ${ }^{\circledR}$ HB80 backing

The strength of the ceramic material had quite a strong effect on overall panel behaviour. Core length reduction for an increased ceramic strength was twice higher in comparison with a reduced one.Also, low ceramic strength led to a panel perforation. The most plausible explanation of this fact is that ceramic with higher strength was less shattered and provided better support for comminuted material under the projectile tip. The results of the previous work [42] are in a good agreement with this assumption. It was shown that a material strength directly influenced a crack pattern of a ceramic target. A strength reduction caused the increase of the area where the material was highly shattered and vice versa.

\section{Conclusion}

New mesoscale model of alumina ceramic was developed and verified through comparison with the known experimental data. The model was used to compare the highvelocity impact efficiency of different mosaic panel constructions. The following remarks and observations can be made:

- Aluminium AA 5083 backing provides stronger support for the ceramic-faced layer in comparison with composite one and increases core erosion. However, using Dyneema ${ }^{\circledR}$ HB80 UD composite allows reducing backing areal density more than two and a half times keeping possibilities to stop a high-velocity projectile.

- Impacts on the conjunctions of two or three hex tiles are less dangerous in comparison with a direct impact in the centre of a ceramic tile if there are no lateral gaps between elements. 
- Lateral gaps between tiles decrease the overall highvelocity performance of the mosaic panel.

- Ceramic tiles with higher strength provide better performance.

\section{Acknowledgment}

This work was financially supported by the Russian Science Foundation (project No. 18-79-00069).
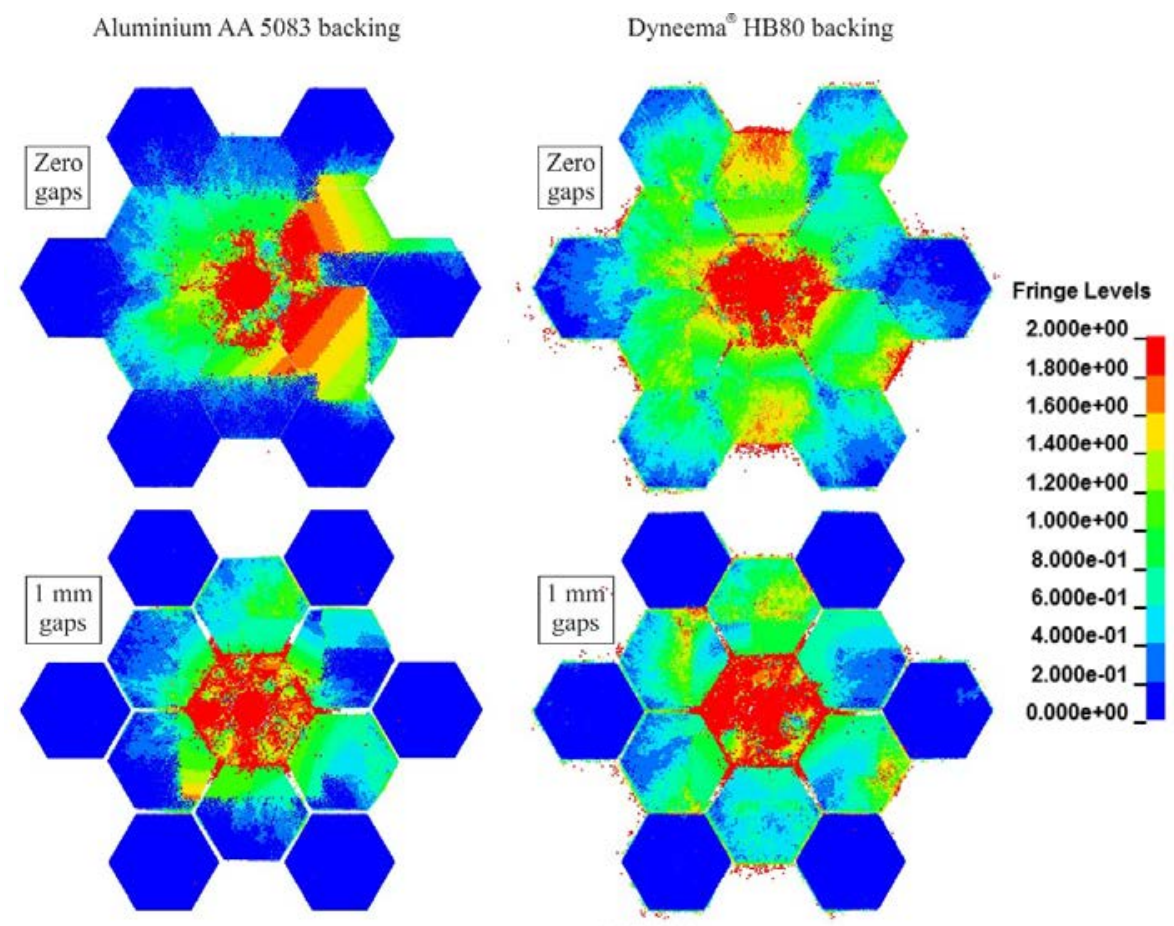

Fig. 10. Overall displacements in ceramic layers after impact

\section{References}

1. Florence A.L. Interaction of projectiles and composite panel - Part I, Report AMRA CR 67-05 (F). Stanford Research Institute, 1967.

2. Florence A.L. Interaction of projectiles and composite panel - Part II, Report AMRA CR 67-05 (F). Stanford Research Institute, 1969.

3. Wilkins M.L., Honodel C.A., Swale D. An approach to the study of light armor. Livermore: Lawrence Radiation Laboratory; June 1967. UCRL-50284.

4. Wilkins M.L., Cline C.F., Honodel C.A. Fourth progress report of light panel program (Report UCRL-50694). Livermore: Lawrence Radiation Laboratory, University of California, 1969.

5. Wilkins M.L. Mechanics of penetration and perforation. International Journal of Engineering Science. 1978, vol. 16, pp. 793-807.

6. Roylance D., Wilde A., Tocci G. High-velocity Impact of Textile Structures. Textile Research Journal. 1973, vol. 43(1), pp. 34-41. DOI:10.1177/004051757304300105.

7. Briscoe B.J., Motamedi F. The high-velocity impact characteristics of aramid fabrics: The influence of interface friction. Wear. 1992, vol. 158(1-2), pp. 229-247. DOI:10.1016/00431648(92)90041-6.

8. Cunniff P.M. An Analysis of the System Effects in Woven Fabrics under High-velocity Impact. Textile Research Journal. 1992, vol. 62(9), pp. 495-509. DOI: 10.1177/004051759206200902.

9. Gu B. Analytical modeling for the high-velocity perforation of planar plain-woven fabric target by projectile. Composites Part B: Engineering. 2003, vol. 34(4), pp. 361-71. DOI:10.1016/S13598368(02)00137-3.
10. Naik N.K., Shrirao P. Composite structures under highvelocity impact. Composite Structures. 2004, vol. 66(1-4), pp. 579-90. DOI:10.1016/j.compstruct.2004.05.006.

11. Chocron S., Figueroa E., King N., Kirchdoerfer T., Nicholls A.E., Sagebiel E., Weiss C., Freitas C.J. Modeling and validation of full fabric targets under high-velocity impact. Composites Science and Technology. 2010, vol. 70, pp. 20122022. DOI:10.1016/j.compscitech.2010.07.025.

12. Zhikharev M.V., Sapozhnikov S.B. Two-scale modeling of high-velocity fragment GFRP penetration for assessment of high-velocity limit. International Journal of Impact Engineering. 2017, vol. 101, pp. 42-48. DOI:10.1016/j.jimpeng.2016.08.005.

13. Sapozhnikov S.B., Kudryavtsev O.A., Zhikharev M.V. Fragment high-velocity performance of homogenous and hybrid thermoplastic composites. International Journal of Impact Engineering. 2015, vol. 81, pp. 8-16. DOI: 10.1016/j.ijimpeng.2015.03.004.

14. Bless S.J., Rosenberg Z., Yoon B. Hypervelocity penetration of ceramics. International Journal of Impact Engineering. 1987, vol. 5(1-4), pp. 165-171. DOI:10.1016/0734-743X(87)90036-4.

15. Rosenberg Z., Yeshurun Y. The relationship between high-velocity efficiency and compressive strength of ceramic tiles. International Journal of Impact Engineering. 1988, vol. 7(3), pp. 357-362. DOI:10.1016/0734-743X(88)90035-8.

16. Sternber J. Material properties determining the resistance of ceramics to high velocity penetration. Journal of Applied Physics. 1989, vol.65, 3417. DOI:10.1063/1.342659.

17. Woodward R.L., Baxter B.J. High-velocity evaluation of ceramics: influence of test conditions. International Journal of 
Impact Engineering. 1994, vol. 15(2), pp. 119-24. DOI: 10.1016/S0734-743X(05)80024-7.

18. Holmquist T.J., Johnson G.R. Response of silicon carbide to high velocity impact. Journal of Applied Physics. 2002, vol. 91, 5858. DOI:10.1063/1.14689.

19. Holmquist T.J., Johnson G.R. Modeling prestressed ceramic and its effect on high-velocity performance. International Journal of Impact Engineering. 2005, vol. 31, pp. 113-127. DOI:10.1016/j.ijimpeng.2003.11.002.

20. Seagraves A., Radovitzky R. Large-scale 3D modeling of projectile impact damage in brittle plates. Journal of the Mechanics and Physics of Solids. 2015, vol. 83, pp. 48-71. DOI: 10.1016/j.jmps.2015.06.001.

21. Hetherington J.G., Rajagopalan B.P. An investigation into the energy absorbed during high-velocity perforation of composite panels. International Journal of Impact Engineering. 1991, vol. 11(1), pp. 33-40. DOI:10.1016/0734-743X(91)90029-F.

22. Navarro C., Martinez M.A., Cortés R., Sánchez-Gálvez V. Some observations on the normal impact on ceramic faced panels backed by composite plates. International Journal of Impact Engineering. 1993, vol. 13(1), pp. 145-156. DOI:10.1016/0734743X(93)90113-L.

23. Horsfall I., Buckley D. The effect of through-thickness cracks on the high-velocity performance of ceramic panel systems. International Journal of Impact Engineering. 1996, vol. 18(3), pp. 309-318. DOI:10.1016/0734-743X(96)89051-8.

24. Chocron-Benloulo I.S., Sanchez-Galvez V. A new analytical model to simulate impact onto ceramic/composite armors. International Journal of Impact Engineering. 1998, vol. 21(6), pp. 461-471. DOI:10.1016/S0734-743X(98)00006-2.

25. Mahfuz H., Zhu Y., Haque A., Abutalib A., Vaidya U., Jeelani S., Gama B., Gillespie J., Fink B. Investigation of highvelocity impact on integral armor using finite element method. International Journal of Impact Engineering. 2000, vol. 24(2), pp. 203-217. DOI:10.1016/S0734-743X(99)00047-0.

26. Fawaz Z., Zheng W., Behdinan K. Numerical simulation of normal and oblique high-velocity impact on ceramic composite panels. Composite Structures. 2004, vol. 63(3-4), pp. 387-395. DOI:10.1016/S0263-8223(03)00187-9.

27. Shokrieh M.M., Javadpour G.H. Penetration analysis of a projectile in ceramic composite armor. Composite Structures. 2008, vol. 82(2), pp. 269-276. DOI: 10.1016/j.compstruct.2007.01.023.

28. Krishnan K., Sockalingam S., Bansal S., Rajan S.D. Numerical simulation of ceramic composite armor subjected to high-velocity impact. Composites: Part B. 2010, vol. 41, pp. 8393. DOI:10.1016/j.compositesb.2010.10.001.

29. Liu W., Chen Z., Chen Z., Cheng X., Wang Y., Chen X., et al. Influence of different back laminate layers on high-velocity performance of ceramic composite armor. Materials and Design. 2015, vol. 87, pp. 421-427. DOI: 10.1016/j.compositesb.2015.08.071.

30. P.J. Hazell. Ceramic Panel: Design and Defeat Mechanisms. Canberra: Argos Press; 2006.

31. Bracamonte L., Loutfy R., Yilmazcoban I.K., Rajan S.D. Design, manufacture, and analysis of ceramic-composite armor. In: Bhatnagar A, editor. Lightweight High-velocity Composites (Second Edition) - Military and Law-Enforcement applications. Woodhead Publishing Limited; 2016. p. 349-367. DOI:10.1016/B978-0-08-100406-7.00012-X.

32. Lanz W. Initial Tests on Ceramics in Composite Armor, Ceramic Armor Material by Design. ACerS, Ceramic Transactions. 2002, vol. 134, pp. 63-72.

33. Karandikar P., Givens B., Liszkiewicz A., Wong S., Aghajanian M. Effects of Novel Geometric Designs on the High- velocity Performance of Ceramics, in: Advances in Ceramic Armor X: A Collection of Papers Presented at the 38th International Conference on Advanced Ceramics and Composites January 27-31, 2014 (ed J. C. LaSalvia), John Wiley \& Sons, Inc., Hoboken, NJ, USA. DOI:10.1002/9781119040590.ch2.

34. Stanislawek S., Morka A., Niezgoda T. Multisphere Ceramic Composite Concept and its Numerical Study of the High-velocity Response. Key Engineering Materials. 2011, vol. 471-472, pp. 11361141. DOI:10.4028/www.scientific.net/KEM.471-472.1136.

35. Stanislawek S., Morka A., Niezgoda T. A Composite Consisting of a Set of Hexagonal Ceramic Bars - The Numerical Study of the High-velocity Resistance. Key Engineering Materials. 2011, vol. 471-472, 1142-1146. DOI:10.4028/www.scientific.net/KEM.471-472.1142.

36. Stanislawek S., Morka A., Niezgoda T. Pyramidal ceramic armor ability to defeat projectile threat by changing its trajectory. Bulletin of the Polish Academy of Sciences: Technical Sciences. 2015, vol. 63(4), pp. 843-849. DOI:10.1515/bpasts-2015-0096.

37. Hazell P.J., Roberson C.J., Moutinho M. The design of mosaic panel: The influence of tile size on high-velocity performance. Materials and Design. 2008, vol. 29, pp. 1497-1503. DOI:10.1016/j.matdes.2008.03.003.

38. Wang Q., Chen Z., Chen Z. Design and characteristics of hybrid composite armor subjected to projectile impact. Materials and Design. 2013, vol. 46, 634-639. DOI:10.1016/j.matdes.2012.10.052.

39. Holmquist T.J., Johnson G.R. A computational constitutive model for brittle materials subjected to large strains, high strain rates, and high pressures. In: Meyers M.A., Murr L.E., Staudhammer K.P., editors. Proceedings of EXPLOMET Conference. San Diego: Marcel Dekker Inc., New York. 1992, pp. 1075-1081.

40. Holmquist T.J., Johnson G.R. An improved computational constitutive model for brittle materials. In: S.C. Schmidt, J.W. Shaner, G.A. Samara, M. Ross, editors. High-Pressure Science and Technology - 1993. United States of America: AIP Press. 1994, pp. 981-984. DOI:10.1063/1.46199.

41. Carton E., Roebroeks G. Testing method for ceramic armor and bare ceramic tiles. Ceramic Engineering and Science Proceedings. 2014, vol. 35(4), pp. 1-12. DOI:10.13140/2.1.1585.3762.

42. O.A. Kudryavtsev, S.B. Sapozhnikov. Numerical simulations of ceramic target subjected to high-velocity impact using combined DEM/FEM approach. International Journal of Mechanical Sciences. 2016, vol. 114, pp. 60-70. DOI:10.1016/j.ijmecsci.2016.04.019.

43. Advanced Alumina. https://www.coorstek.com/media/ 1715/advanced-alumina-brochure.pdf (accessed 22.09.2016)

44. Karajan N., Han Z., Ten H., Wang J. Interaction possibilities of bonded and loose particles in LS-DYNA. DYNAmore GmbH, Livermore Software Technology Corp., 9th European LS-DYNA Conference, 2013. http://www.dynalook.com/ 9th-european-ls-dyna-conference/interactionpossibilities-of-bonded-and-loose-particles-in-ls-dyna-r

45. LSTC. LS-DYNA R7.0 user's manual; 2013 $<$ http://www.lstc.com>.

46. Cundall P.A., Strack O.D.L. A discrete numerical model for granular assemblies. Geotechnique. 1979, vol. 29(1), pp. 47-65. DOI:10.1680/geot.1979.29.1.47.

47. ASTM C1161-13, Standard Test Method for Flexural Strength of Advanced Ceramics at Ambient Temperature, ASTM International, West Conshohocken, PA, 2013. DOI:10.1520/C1161

48. Horsfall I., Edwards M.R., Hallas M.J. High-velocity and physical properties of highly fractured alumina. Advances in Applied Ceramics. 2013, vol. 109(8), vol. 498-503. DOI:10.1179/174367610X12804792635341 
49. Informacionnyj sbornik №43. Bronevye protivopul'nye materialy / CHistyakov E.N., Zarya N.V., Mahov B.F. i dr. - M.: OAO NII Stali, 2010. - $288 \mathrm{~s}$.

50. Armor Clothes, Classification and General Technical Requirements, GOST R 50744-95, September 2013.

51. Johnson G.R., Cook W.H.A constitutive model and data for metals subjected to large strains, high strain rates and high temperatures. Proceedings: Seventh International Symposium on High-velocitys. 1983, pp. 541-547.

52. Clausen A.H., Børvik T., Hopperstad O.S., Benallal A. Flow and fracture characteristics of aluminium alloy AA5083H116 as function of strain rate, temperature and triaxiality. Materials Science and Engineering A. 2004, vol. 364, pp. 260272. DOI:10.1016/j.msea.2003.08.027

53. Kędzierski P., Morka A., Sławiński G., Niezgoda T, Optimization of two-component panel. Bulletin of the Polish Academy of Sciences: Technical Sciences. 2015, vol. 63(1), pp. 173-179. DOI:10.1515/bpasts-2015-0020.

54. Carbajal L., Jovicic J., Kuhlmann H. Assault riffle bulletexperimental characterization and computer (FE) modelling. In: Conference proceedings of the Society for Experimental Mechanics Series. Experimental and applied mechanics. 2011, vol. 6, pp. 651-668. DOI:10.1007/978-1-4614-0222-0_77.

55. Appleby-Thomas G.J., Hazell P.J., Millett J., Bourne N.K. Deviatoric response of an panel-grade aluminium alloy. AIP Conference Proceedings. 2009, vol. 1195(1), pp. 533-536. DOI:10.1063/1.3295192.
56. Børvik T., Hopperstad O.S., Berstad T., Langseth M. A computational model of viscoplasticity and ductile damage for impact and penetration. European Journal of Mechanics A/Solids. 2001, vol. 20(5), pp. 685-712. DOI:10.1016/S09977538(01)01157-3.

57. Cockroft M.G., Latham D.J. Ductility and the workability of metals. Journal of the Institute of Metals. 1968, vol. 96, pp. 33-39.

58. Børvik T., Dey S., Clausen A.H. Perforation resistance of five different high-strength steel plates subjected to small-arms projectiles. International Journal of Impact Engineering. 2009, vol. 36, pp. 948-964. DOI:10.1016/j.ijimpeng.2008.12.003.

59. Feli S., Asgari M.R. Finite element simulation of ceramic/composite armor under high-velocity impact. Composites: Part B. 2011, vol. 42, pp. 771-780. DOI:10.1016/j.compositesb.2011.01.024.

60. Kudryavtsev O.A., Sapozhnikov S.B. Yarn-level modelling of woven and unidirectional thermoplastic composite materials under high-velocity impact. PNRPU Mechanics Bulletin. 2016, No. 3, pp. 108-119. DOI:10.15593/perm.mech/2016.3.07

61. Liu W., Chen Z., Cheng X., Wang Y., Amankwa A.R., Xu J. Design and high-velocity penetration of the ceramic composite armor. Composites Part B. 2016, vol. 84, pp. 33-40. DOI:10.1016/j.compositesb.2015.08.071.

62. Mohotti D., Ngo T., Raman S. N., Mendis P. Analytical and numerical investigation of polyurea layered aluminium plates subjected to high velocity projectile impact. Materials and Design. 2015, vol. 82, pp. 1-17. DOI:10.1016/j.matdes.2015.05.036. 